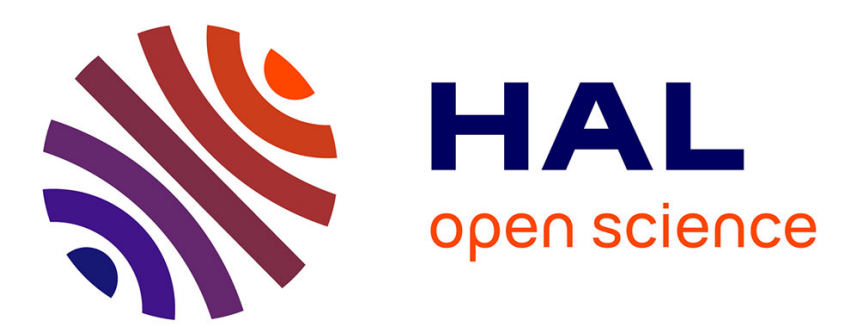

\title{
Determination of exon 7 SMN1 deletion in Iranian patients and heterozygous carriers by quantitative real-time PCR.
}

\author{
Mohammad Taghi Akbari, Mehrdad Noruzinia, Hossein Mozdarani, \\ Mohammad Hamid
}

\section{To cite this version:}

Mohammad Taghi Akbari, Mehrdad Noruzinia, Hossein Mozdarani, Mohammad Hamid. Determination of exon 7 SMN1 deletion in Iranian patients and heterozygous carriers by quantitative real-time PCR.. Journal of Genetics, 2011, 90 (1), pp.133-136. 10.1007/s12041-011-0038-1 . pasteur-00746420

\section{HAL Id: pasteur-00746420 \\ https://hal-riip.archives-ouvertes.fr/pasteur-00746420}

Submitted on 29 Oct 2012

HAL is a multi-disciplinary open access archive for the deposit and dissemination of scientific research documents, whether they are published or not. The documents may come from teaching and research institutions in France or abroad, or from public or private research centers.
L'archive ouverte pluridisciplinaire HAL, est destinée au dépôt et à la diffusion de documents scientifiques de niveau recherche, publiés ou non, émanant des établissements d'enseignement et de recherche français ou étrangers, des laboratoires publics ou privés. 


\title{
Determination of exon 7 SMN1 deletion in Iranian patients and heterozygous carriers by quantitative real-time PCR
}

\author{
MOHAMMAD TAGHI AKBARI ${ }^{1,2 *}$, MEHRDAD NORUZINIA ${ }^{1}$, HOSSEIN MOZDARANI $^{1}$ \\ and MOHAMMAD HAMID ${ }^{3}$ \\ ${ }^{1}$ Department of Medical Genetics, Faculty of Medical Sciences, Tarbiat Modares University, Tehran 14115-111, Iran \\ ${ }^{2}$ Tehran Medical Genetics Laboratory, No. 297, Taleghani Street, Tehran 1598619617, Iran \\ ${ }^{3}$ Molecular Medicine Division, Biotechnology Research Center, Pasteur Institute of Iran, No. 69, Pasteur Ave, \\ 13164 Tehran, Iran
}

\begin{abstract}
[Akbari M. T., Noruzinia M., Mozdarani H. and Hamid M. 2011 Determination of exon 7 SMN1 deletion in Iranian patients and heterozygous carriers by quantitative real-time PCR. J. Genet. 90, 133-136]
\end{abstract}

\section{Introduction}

Spinal muscular atrophy (SMA) is a neuromuscular disorder caused by the degeneration of motor neurons of the spinal cord anterior horns, leading to progressive atrophy of proximal muscles, paralysis, respiratory failure, and even infant death. Patients with SMA are classified into three types, based on the age at onset and clinical severity (Munsat and Davies 1992; Wirth et al. 1995): type I (MIM 253300) is the most severe form, type II (MIM 253550) is the intermediate form, and type III (MIM 253400) is the mildest form. With an incidence of $1 / 6000$ to $1 / 10000$ and a carrier frequency of $1 / 40$ to $1 / 50$, SMA is the second most frequent autosomal recessive disease in Europeans (Pearn 1980). The SMA determining gene called the 'survival motor neuron' gene $(S M N)$ is present on $5 \mathrm{q} 13$ in two copies, SMN1 and $S M N 2$, which differ by only five nucleotide exchanges within their $3^{\prime}$ ends (Lefebvre et al. 1995). Two of these base-pair exchanges, located in exons 7 and 8 (which allow SMN1 to be distinguished from $S M N 2$ ) currently are used for direct diagnosis of SMA. Therefore, the first step in this test is to amplify specifically $S M N 1$ exon 7 or exon 8 and later on subjecting the PCR product to restriction digestion, a PCR-RFLP approach (Scheffer et al. 2001). In a study of 1122 patients with type I, type II, or type III SMA it was shown that in about $94 \%$ of SMA patients (in all three types) homozygous absence of $S M N 1$ is responsible for this disease (Scheffer et al. 2000). Approximately half of the remaining patients were identified as compound heterozygote (with deletions and intragenic SMN1 mutations), whereas the other half, without SMN1 mutations, were considered as distinct genetic entities (Wirth et al. 1999). The carrier test for

*For correspondence. E-mail: mtakbari@modares.ac.ir.
SMA is an important issue in genetic counselling as the carrier frequency in population is high. Nevertheless, the aforementioned PCR-RFLP test was capable of only distinguishing individuals homozygous for the deletion, and could not differentiate heterozygous carriers from normal individuals. Until now, several quantitative PCR methods for SMN1 analysis have been developed for carrier detection (McAndrew et al. 1997; Gerard et al. 2000; Scheffer et al. 2000; Martin et al. 2002). However, these methods were error prone. Recently reported quantitative real-time PCR assays allow the specific amplification of only SMN1 gene and have become powerful tool to avoid these problems (Feldkötter et al. 2002; Lee et al. 2004).

In consideration of these defects and in line with the latter references, we have developed a reliable quantitative realtime PCR method using SMN1 gene specific primers and SYBR Green I dye for the SMA carrier detection in Iranian population. Here, we report the results of this quantitative analysis of SMA patients, their parents and individuals suspected of being carriers due to positive pedigree.

\section{Materials and methods}

\section{Patients}

We had access to 15 DNA samples from the parents of 10 SMA patients whose genotypes were already identified to be homozygous for SMN1 exon 7 deletion by PCR-RFLP approach. Although these parents could not be examined by the aforementioned approach for their SMN1 exon 7 deletion status, they could be considered logically to be obligate carriers of this deletion. Therefore, in setting up gene dosage experiments these parents were considered as obligate carriers. This assumption proved correct and all 15 individuals

Keywords. spinal muscular atrophy; exon 7 deletion; SMN1 gene; real-time PCR. 
were demonstrated to be heterozygous for exon 7 deletion by dosage analysis.

Apart from this group, the SMA patients whose genotypes could not be identified by PCR-RFLP method, and individuals suspected of being carriers because of having a child or children expired of SMA, or belonging to a pedigree with positive SMA history, were also recruited in this study. In total, 108 subjects were analysed.

Genomic DNA was extracted from peripheral blood of all samples using the salting out method (Miller et al. 1988). DNA samples that had purity in the range of 1.5 $1.8(260 \mathrm{~nm} / 280 \mathrm{~nm}$ ratio) were selected for quantitative analysis.

\section{Quantitative real-time PCR of SMN1 exon 7}

Gene dosage of different samples was determined by standardizing the copy number of SMN1 gene in a sample to the copy number of a single copy reference gene, i.e. albumin. Albumin fulfills the criteria of a reference gene in which it is free of pseudogenes and multiple copy numbers which leads to false results due to amplification from excessive genomic DNA. Further, a segment of the albumin gene, exon 12, was chosen by optimization which had similar amplification efficiency during log-linear phase compared to the target SMN1 exon 7 DNA segment.

The quantitative real-time PCR assay utilized primers that specifically amplified $S M N 1$ gene. To distinguish SMN1 from $S M N 2$ in the amplification reactions, $3^{\prime}$ ends of the primers were designed to end on the $S M N 1$ specific sequence in exon 7 at position 6 and intron 7 at position +2 : forward primer: 5'-CCTTTTATTTTCCTTACAGGGTTTC-3'; reverse primer: 5'-GATTGTTTTACATTAACCTTTCAACTTTT-3' (Lee et al. 2004). The primers for the reference gene, exon 12 of human serum albumin were: forward primer: 5'-AGCTATCCGTGGTCCTGAAC-3'; reverse primer: 5'TTCTCAGAAAGTGTGCATATATCTG-3' (Lee et al. 2004). PCR mixture contained $4 \mu \mathrm{L}$ of SYBR Green ${ }^{\circledR}$ PCR master mix (Roche, Mannheim, Germany), 5 ng of genomic DNA, and 10 pmol of SMN1 and albumin primers, which was determined after the analysis of the optimal concentrations of each primer. Each sample was run in triplicate. The PCR condition consisted of initial denaturation step of $95^{\circ} \mathrm{C}$ for $10 \mathrm{~min}$, followed by 35 cycles of denaturation at $95^{\circ} \mathrm{C}$ for $15 \mathrm{~s}$ and $58^{\circ} \mathrm{C}$ for $15 \mathrm{~s}$.

\section{Generation of standard curves}

To establish an amplification efficiency for the two segments of the target and reference DNA, and to make sure these efficiencies are similar, it was required to generate standard curves. DNA derived from normal individual was used for generation of the calibration curve for Alb and SMN1 genes. To generate a standard curve for each gene, we amplified DNA from serial dilution with four different magnitudes of concentrations. The second derivative maximum method automatically calculated fractional cycle number, or crossing point, where the fluorescence rose above background. PCR efficiency was calculated by the RotorGene RG3000 real-time PCR machine (Corbett Research, Sydney, Australia) from this formula: efficiency $=\left[10^{-1 / \text { slope }}\right]-1$ (Vaerman et al. 2004). As can be seen from the standard curves (figure 1), efficiency of Alb and SMN1 genes were 0.9 and 0.91 , respectively. Therefore, we concluded that the efficiencies of the target and reference were the same. The slope obtained from standard curves for $A l b$ and SMN1 were 3.58 and 3.54 , respectively. Also the coefficient of determination $\left(R^{2}\right)$ for our target and reference genes was calculated to be equal to 0.99 (figure 1). This indicates that there is a correlation between the changes in DNA concentrations and differences between $\mathrm{Ct}$ values.

\section{Data analysis}

The gene copy numbers of the samples were determined by the following formula: $\Delta \Delta \mathrm{Ct}=(\Delta \mathrm{Ct}$ albumin (calibrator sample) $-\triangle \mathrm{Ct} S M N 1$ (calibrator sample)) $-(\Delta \mathrm{Ct}$ albumin (unknown sample) $-\triangle \mathrm{Ct} S M N 1$ (unknown sample)). The last step in quantitation was to transform these values to absolute values. The relative gene copy numbers were calculated by using the ratio formula (ratio $=2^{-\Delta \Delta \mathrm{Ct}}$ ). Using this method it was expected to be about 1 in normal control, 0.5 in carriers and 0 in patients with SMA (Lee et al. 2004).

\section{Results}

For establishing the dosage profile of the obligate carriers, they were compared with normal individuals as controls. In this experiment, few patients identified by PCR-RFLP as homozygous for exon 7 deletion were also tested as negative control. The Ct value of SMN1 and albumin (reference gene) was almost identical as it can be seen on the amplification plots of a normal control (figure 1A). For parents of SMA patients, carrying only one $S M N 1$ gene copy, the Ct values of SMN1 showed an increase in comparison to albumin (figure 1B). For the SMA patients, the albumin gene amplified as in normal controls, but the SMN1 gene did not amplify as expected (figure 1C). Therefore, there were no visible products for the SMN1 gene in SMA patients. The range of measured $\Delta \Delta \mathrm{Ct}$ ratios in 15 obligate carriers was between 0.35 and 0.70 (table 1).

The samples with unknown genotype from SMA patients, their parents and individuals suspected to be carriers were examined and the following results were obtained. According to the range of measured $\Delta \Delta \mathrm{Ct}$ ratios, 52 patients were identified as carriers, and 26 patients indicated to be normal as far as exon 7 deletion was concerned. Fifteen patients were also detected as homozygous for exon 7 deletion (table 1). Therefore, a total of 108 cases were identified. Of those, 20 cases were fetuses diagnosed prenatally; five normal, nine carriers and six affected were identified. 

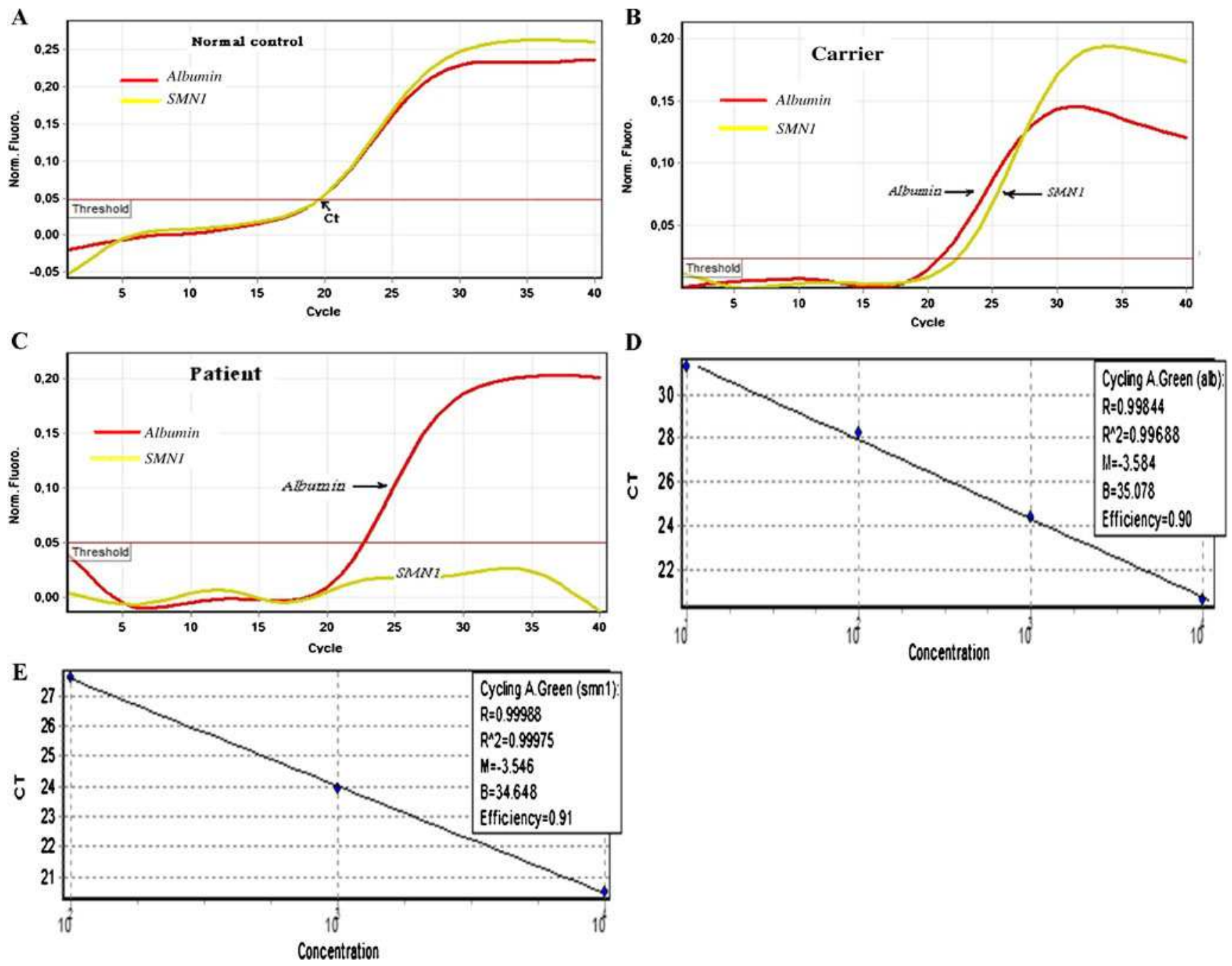

Figure 1. Real-time amplification plots of $S M N 1$ and albumin of: (A) healthy normal control ( $\triangle \triangle \mathrm{Ct}$ ratio 1); (B) carrier with one $S M N 1$ copy $(\Delta \Delta$ Ct ratio 0.5$)$; (C) patients with SMA of homozygous absence of SMN1 ( $\triangle \Delta \mathrm{Ct}$ ratio 0.00 , no amplification of $S M N 1)$; (D \& E) real-time standard curves for reference and target genes.

\section{Discussion}

Of the patients and fetuses who were referred to our laboratory, almost a quarter could be identified as homozygous for exon 7 deletion by the conventional PCR-RFLP approach. Due to limitations of this test, the suspected carriers could not be examined. However, by employing real-time PCR dosage

Table 1. Real-time quantitative analysis of $S M N 1$ gene copy number using a comparative $\mathrm{Ct}$ method $(\Delta \Delta \mathrm{Ct}$ ratio) in patients, carriers obligate carriers and normal individuals.

\begin{tabular}{lcc}
\hline & \multicolumn{2}{c}{$\Delta \Delta$ Ct ratio } \\
\cline { 2 - 3 } Subject & Mean & Range \\
\hline Patient $(n=15)$ & 0.00 & $0.00-0.00$ \\
Obligate Carrier $(n=15)$ & 0.49 & $0.35-0.70$ \\
Carrier $(n=52)$ & 0.51 & $0.32-0.71$ \\
Normal $(n=26)$ & 1.004 & $0.81-1.26$ \\
\hline
\end{tabular}

analysis, apart from identifying those cases correctly, asymptomatic carriers and patients with one deleted allele were successfully differentiated. Carrier detection for autosomal recessive disorders with no easily differentiating biochemical or hematological marker is an ultimate strategy in the context of genetic counselling. Therefore, a rapid and sensitive carrier test for SMA as a lethal and disabling condition in a population such as Iran with a high rate of consanguineous marriage can make a big difference in family planning and prenatal diagnosis.

Another important feature of this test is that since homozygous deletion of SMN1 exon 7 is the most common lesion causing all three subtypes of SMA, it can be used with high degree of confidence that large proportion of patients and carriers can be identified accurately in a short span of time.

We aimed at identifying the SMA carrier in Iran based on real-time PCR with the SYBR Green I dye using the comparative $\mathrm{Ct}$ method. Many samples were analysed in triplicates. When we analysed copy numbers of the SMN1 gene 
in peripheral blood mononuclear cells, we found that normal subjects had the highest number of gene copy with $0.81-1.26$ range, SMA patients did not have any copy $(0.00)$, and carriers range between 0.32 and 0.71 . This assay has the advantage of being carried out in a closed system with no need for post-PCR processing common in other assay formats.

This study was carried out based on one reference gene. The amplification efficiency of Alb and SMN1 genes were derived from the standard curve. As trendlines slopes are a prerequisite for accurate copy number assessment, it was measured and it was within acceptable range $(-3.6<$ slope $<3.1$ ). Therefore, PCR efficiencies of both genes were approximately equal. Standard curves for target and reference genes were prepared over serially diluted genomic DNA samples. So we believe that one reference gene is sufficient to assess the copy number of the target gene. However, in expression studies more than one reference gene might be utilized according to the type of study. To our knowledge, the majority of studies which have dealt with assessing the copy number of a gene by real-time PCR, have only used one reference gene (Lee et al. 2004; Ruiz-Ponte et al. 2006; Shadrina et al. 2007; Passon et al. 2009).

In conclusion, we have developed a quantitative real-time PCR test which can evaluate comprehensively the status of SMN1 exon 7 deletion in carriers, affected individuals and normal people which can be also applied prenatally.

\section{Acknowledgement}

The authors appreciate the collaboration of patients and their families as well as their clinicians. We thank the staff of Tehran Medical Genetics Laboratory especially Mrs S. Zare and Dr Karimipoor for their valuable contributions. This work was supported in part by Tarbiat Modares University through Research Grant allocated to MTA.

\section{References}

Feldkötter M., Schwarzer V., Wirth R., Wienker T. and Wirth B. 2002 Quantitative analyses of SMN1 and SMN2 based on realtime lightCycler PCR: fast and highly reliable carrier testing and prediction of severity of spinal muscular atrophy. Am. J. Hum. Genet. 70, 358-368.

Gerard B., Ginet N., Matthijs G., Evrard P., Baumann C., Da Silva F. et al. 2000 Genotype determination at the survival motor neuron locus in a normal population and SMA carriers using competitive PCR and primer extension. Hum. Mutat. 16, 253-263.
Lee T., Kim S., Lee K., Jin H., Koo S., Jo I. et al. 2004 Quantitative analysis of SMN1 gene and estimation of SMN1 deletion carrier frequency in Korean population based on real-time PCR. J. Korean Med. Sci. 19, 870-873.

Lefebvre S., Burglen L., Reboullet S., Clermont O., Burlet P., Viollet L. et al. 1995 Identification and characterization of a spinal muscular atrophy-determining gene. Cell 80, 155-165.

Martin Y., Valero A., del Castillo E., Pascual S. and HernandezChico C. 2002 Genetic study of SMA patients without homozygous SMN1 deletions: identification of compound heterozygotes and characterisation of novel intragenic SMN1 mutations. Hum. Genet. 110, 257-263.

McAndrew P., Parsons D., Simard L., Rochette C., Ray P. and Mendell J. 1997 Identification of proximal spinal muscular atrophy carriers and patients by analysis of SMNT and SMNC gene copy number. Am. J. Hum. Genet. 60, 1411-1422.

Miller S. A., Dykes D. D. and Polesky H. F. 1988 A simple salting out procedure for extracting DNA from human nucleated cells. Nucleic Acids Res. 16, 1215.

Munsat T. and Davies K. 1992 Meeting report: International SMA consortium meeting. Neuromuscul. Disord. 2, 423-428.

Passon N., Pozzo F., Molinis C., Bregant E., Gellera C., Damante G. et al. 2009 A simple multiplex real-time PCR methodology for the SMN1 gene copy number quantification. Genet. Test. Mol. Biomarkers 13, 37-42.

Pearn J. 1980 Classification of spinal muscular atrophies. Lancet 1, 919-922.

Ruiz-Ponte C., Carracedo A. and Barros F. 2006 Duplication and deletion analysis by fluorescent real-time PCR-based genotyping. Clin. Chim. Acta 363, 138-146.

Scheffer H., Cobben J., Mensink R., Stulp R., Van der Steege G. and Buys C. 2000 SMA carrier testing-validation of hemizygous SMN exon 7 deletion test for the identification of proximal spinal muscular atrophy carriers and patients with a single allele deletion. Eur. J. Hum. Genet. 8, 79-86.

Scheffer H., Cobben J., Matthijs G. and Wirth B. 2001 Best practice guidelines for molecular analysis in spinal muscular atrophy. Eur. J. Hum. Genet 9, 484-491.

Shadrina M. I., Semenova E. V., Slominsky P. A., Bagyeva G. H., Illarioshkin S. N., Ivanova S. II. et al. 2007 Effective quantitative real-time polymerase chain reaction analysis of the parkin gene (PARK2) exon 1-12 dosage. BMC Med. Genet. 8, 6.

Vaerman J., Saussoy P. and Ingargiola I. 2004 Evaluation of realtime PCR data. J. Biol. Regul. Homeost. Agents 18, 212-214.

Wirth B., Hahnen E., Morgan K., DiDonato C. J., Dadze A. and Rudnik-Schoneborn S. 1995 Allelic association and deletions in autosomal recessive proximal spinal muscular atrophy: association of marker genotype with disease severity and candidate cDNAs. Hum. Mol. Genet. 4, 1273-1284.

Wirth B., Herz M., Wetter A., Moskau S., Hahnen E. and RudnikSchoneborn S. 1999 Quantitative analysis of survival motor neuron copies: identification of subtle SMN1 mutations in patients with spinal muscular atrophy, genotype-phenotype correlation, and implications for genetic counseling. Am. J. Hum. Genet. 64, $1340-1356$. 